Volume 3

Issue 4 -- Cardiovascular Aging

Article 29

$11-11-2016$

\title{
Are There Advantages to Hiring In-House Training Program Graduates?
}

Jessica J.F. Kram

Dennis J. Baumgardner

Follow this and additional works at: https://aah.org/jpcrr

Part of the Health and Medical Administration Commons, and the Medical Education Commons

\section{Recommended Citation}

Kram JJ, Baumgardner DJ. Are there advantages to hiring in-house training program graduates? J Patient Cent Res Rev. 2016;3:244-5.

Published quarterly by Midwest-based health system Advocate Aurora Health and indexed in PubMed Central, the Journal of Patient-Centered Research and Reviews (JPCRR) is an open access, peer-reviewed medical journal focused on disseminating scholarly works devoted to improving patient-centered care practices, health outcomes, and the patient experience. 
Methods: We included 9 patients with typical atrial flutter for whom mapping and ablation of the CTI was done using Carto mapping as the sole guiding modality. Zero fluoroscopy was achieved in all of them. Another group of 9 matched patients whose ablations were done using the traditional method (i.e. fluoroscopy and Carto guidance) were included as a control.

Results: Both groups had similar baseline characteristics. The total fluoroscopy time and radiation dose in the control group were $12.8 \pm 4.8$ minutes, $230.2 \pm 131.9 \mathrm{mGy}$, respectively. The zero-fluoroscopy group were done while wearing no lead aprons. The average total procedure time was $114.8 \pm 16.9$ minutes in the zero-fluoroscopy group, significantly less than that of the control group $(138.6 \pm 24.3$ minutes; $\mathrm{P}=0.0286)$. The total radiofrequency time was similar in both groups $(15.2 \pm$ 7.4 minutes in zero-fluoroscopy group vs $16 \pm 2.9$ minutes in control group; $\mathrm{P}=0.9294)$. Bidirectional block was achieved in all patients of both groups. No complications were encountered in either group.

Conclusion: To our knowledge, this is the first study of a zerofluoroscopic approach using the Carto mapping system for ablation of the cavotricuspid isthmus in the United States. The approach is feasible and effective in achieving bidirectional block with less average total procedure time.

\section{Determining the Incidence and Factors of Cardiotoxicity in Breast Cancer Patients Treated With Anthracycline and/or Trastuzumab-Containing Regimen at Aurora Health Care}

Stephanie Ghojallu, Matthew Rappelt, Han-Yang Chen, Ruth Perez, Lydia Garlie, Geoffrey Riddell, Yingying Gu, Jun Zhang, Rubina Qamar, Bijoy K. Khandheria, Arshad Jahangir, Yang Shi

Aurora Nursing Administration; Aurora Research Institute; University of Wisconsin-Milwaukee; Hematology/ Oncology, Aurora Health Care; Aurora Cardiovascular Services and Sheikh Khalifa bin Hamad Al Thani Center for Integrative Research on Cardiovascular Aging, Aurora Health Care

Background: Anthracycline and trastuzumab are common breast cancer treatments. While improving survival, they elevate risk of congestive heart failure. The incidence of cardiotoxicity (CTx) with these therapies varies in the literature from $10 \%$ to $59 \%$, higher than those reported in clinical trials $(4 \%-$ $10 \%)$ that excluded patients with preexisting cardiovascular comorbidities. Studies have failed to establish consensus on the risk factors for CTx associated with these therapies.

Purpose: We aim to determine the incidence and risk factors of CTx in breast cancer patients treated with anthracycline and/or trastuzumab at Aurora Health Care.

Methods: A retrospective review of patients with breast cancer who received anthracycline and/or trastuzumab from 2002 to 2011 yielded a total of 2,383 patients. Patients with a left ventricular ejection fraction (LVEF) recorded prior to treatment and at least one follow-up LVEF were included in analysis ( $n=319,13.4 \%$ of total cohort). Database queries and electronic medical records review (assisted by an inhouse natural language processing tool) retrieved data on demographics, comorbidities, congestive heart failure symptoms, oncological treatments and LVEF. The study outcome was CTx, defined as a $\geq 10 \%$ decrease in LVEF to a level of $<55 \%$. Chi-squared and Fisher's exact tests were used for categorical variables to test differences in patient characteristics by CTx status (yes/no). Multivariate logistic regression analyses examined the association between risk factors and CTx.

Results: Average age of the patients was $54.9 \pm 12.1$ years; the cohort was comprised of $50.5 \%$ with obesity, $44.2 \%$ with smoking history and $47.3 \%$ with hypertension. A total of 79 patients developed CTx, an incidence of $24.8 \%$. Multivariable analysis identified divorced/widowed marital status (odds ratio [OR]: 2.70, 95\% confidence interval [CI]: 1.26-5.77), history of structural/electrophysiological (EP) cardiac disease (OR: 2.66, 95\% CI: 1.24-5.70) and combined anthracycline-trastuzumab therapy (OR: 2.92, 95\% CI: 1.48-5.77) as significant risk factors for CTx.

Conclusion: The incidence of CTx was greater in a community setting for which cardiac history and comorbidities are more diverse than in clinical trials. Consistent with prior literature, our study identified combined treatment with anthracycline and trastuzumab as a risk factor for CTx. Our study also suggests divorced/widowed marital status and prior structural/EP cardiac disease as additional risk factors for CTx. Further prospective studies are warranted for verification. We advocate for pre- and posttreatment cardiac monitoring of patients receiving these two therapies.

\section{Are There Advantages to Hiring In-House Training Program Graduates?}

Jessica J.F. Kram, Dennis J. Baumgardner

Department of Family Medicine, Aurora UW Medical Group; Center for Urban Population Health

Background: Several studies have compared international graduates on measures of performance, quality and satisfaction. No studies have compared internally versus externally hired graduates in relation to these measures.

Purpose: To identify if there is a difference in hiring patterns and care management (CM)/patient satisfaction (PS) scores between internal and external graduate hires.

Methods: We conducted a quality improvement study on graduates hired by Aurora Health Care from Jan. 1, 2006, to Dec. 14, 2015. CM scores were determined based on hire date. PS scores were calculated based on the calendar year, regardless of exact hire date. PS scales for scoring changed in mid-2010. Hired graduates with no CM and PS scores, as well as those with less than one year of employment, were excluded. Means were compared using two-sample t-tests and regression analysis. Categorical variables were analyzed using chi-squared and Fisher's exact test, as appropriate.

Results: Study population $(\mathrm{N}=108)$ characteristics included: mean age 38.0 years, $62.0 \%$ female gender and $56.5 \%$ 
white race. The majority of those hired (mean starting FTE $0.99)$ were external graduates $(70.4 \%)$ and family medicine physicians $(50.9 \%)$. Of those hired since $2006,71.3 \%$ are still employed (mean longevity 3.5 years). There was no difference in age, sex, race or employment status between internally and externally hired graduates. Family medicine hires were significantly more likely to be internal graduates compared to internal medicine $(40.0 \%$ vs $13.6 \%, \mathrm{P}=0.03$ ) and all other physician specialties combined $(40.0 \%$ vs $18.9 \%, \mathrm{P}=0.03)$. First-year CM scores did not differ by age, sex, race, year offer accepted, or external versus internal residency. Family medicine hires had significantly lower initial $\mathrm{CM}$ scores (2.76 vs 3.14, $\mathrm{P}=0.009)$ when compared to other physician specialties. However, second-year CM scores showed no difference between family medicine and other physicians. First-year PS (scale one) scores were significantly higher with younger age $(\mathrm{P}=0.03)$, female sex $(\mathrm{P}=0.04)$ and internal graduates $(\mathrm{P}=0.04)$. Younger age and female sex remained predictors of higher PS for second-year scores. No statistical difference was noted with use of scale two for PS scoring.

Conclusion: Care management scores do not differ between internally and externally hired graduates; patient satisfaction scores differed based on scale used. Further study is needed to determine internal hiring disparities between specialties and if $\mathrm{CM}$ scores are lower in those hires with more items to be scored.

\section{Additional Presentations}

The following citations reflect the remaining 2016 Aurora Scientific Day presentations, some of which have been published as abstracts or articles in scientific journals.

First Place Oral Presentation: Tjoe J, Dalmar A, Greer D. The role of surgical primary tumor extirpation in de novo stage IV breast cancer in the era of targeted treatment. In: The American Society of Breast Surgeons 2016 Annual Meeting Official Proceedings, Volume XVII. Ann Surg Oncol. 2016;23(3 Suppl):21-23.

Third Place Oral Presentation: Krum D, Erickson L, Hare J, Choudhuri I, Rowe D, Sra J. Three-dimensional cardiac mapping using only single-plane fluoroscopy. Orally presented at Aurora Scientific Day, Milwaukee, WI, May 25, 2016.

First Place Poster: Rizvi F, Siddiqui R, DeFranco A, Holmuhamedov A, Xu H, Emelyanova L, Ross G, Shi Y, Holmuhamedov E, Tajik AJ, Jahangir A. Simvastatin prevents TGF- $\beta 1$-induced SMAD2/3 phosphorylation involved in ventricular fibrosis: role of protein phosphatases. Subsequently presented at the Basic Cardiovascular Sciences 2016 Scientific Sessions, July 18-21, 2016, Phoenix, AZ.
Second Place Poster (tie): Petrovic M, Godic Z, Holmuhamedov A, Kraft K, Negmadjanov U, Emelyanova L, Rizvi F, Ross G, Kress DC, Holmuhamedov E, Tajik AJ, Jahangir A. Functional and structural differences in fibroblasts from atria of patients with and without atrial fibrillation. $J \mathrm{Am}$ Coll Cardiol. 2016;67(13_S):744.

Third Place Poster (tie): Ahmad MN, Ahmad MM, Hussaini SF, Khandheria BK, Jain R, Tajik AJ, Ammar KA. Aortopathy in hypertrophic cardiomyopathy; the association with sinus of Valsalva versus mid ascending aorta: an epidemiological study. J Am Coll Cardiol. 2016;67(13_S):1613.

Third Place Poster (tie): Naeem U, Nangia V, Koeberl R, Mortada ME. Medtronic Carelink Express device usage in midsize emergency department. Heart Rhythm. 2016;13(5):S523.

Greer DM, Zusevics KL, Stehman CM, Kessler CL. Impact of Wisconsin's Project LAUNCH on school readiness: a community quasi-experimental intervention study of K5 students in Milwaukee Public Schools. Orally presented at Aurora Scientific Day, Milwaukee, WI, May 25, 2016.

Shi Y, Rappelt M, Yousefzai R, Sulemanjee N, Zwicke D, Hastings T, Cheema O, Downey F, Crouch J, Thohan V. Novel pre-implant characteristics associated with 12 month risk of gastrointestinal bleeding among patients supported with continuous flow left ventricular assist device therapy. Circulation. 2015;132:A19925.

Dalmar A, Singh M, Heis Z, Katzoff MN, Chua T, Tajik AJ, Jahangir A. The risk of adverse cardiovascular outcomes after bariatric surgery in patients with morbid obesity with and without obstructive sleep apnea. J Am Coll Cardiol. 2016;67(13_S):1885.

Dagnew YW, Greer DM, Kram JJ, Reid K, Siegal EM. Seasonal variation in venous thromboembolism occurrence and associated mortality in Aurora Health Care facilities. Orally presented at Aurora Scientific Day, Milwaukee, WI, May 25, 2016.

Huber ME, Baumgardner DJ, Kram JJ, Lemke MA. Geodemographic features of human blastomycosis in eastern Wisconsin. J Patient Cent Res Rev. 2016;3:90-8.

Aldag E, Fehrenbacher L, Castillo U, Sahajpal AJ, Gunabushanam V, Hussein F, Chadha M, Kramer DJ. Extracorpeal albumin dialysis with molecular adsorbent recirculating system $\left(\mathrm{MARS}^{\circledR}\right)$ and the effect on antimicrobial removal. Poster presented at Aurora Scientific Day, Milwaukee, WI, May 25, 2016.

Flores K, McDearmon S, Phelps B, Kram JJ, Baumgardner DJ, Kotovicz F. FP059: Understanding providers' emotions and thoughts regarding opioid use for the management of chronic non-cancer pain in a family medicine residency program. Presented at Society of 